\title{
Research on the Integration of Environmental Auditing and Economic Responsibility Auditing
}

\author{
Ya-Mei GUAN* Zi-Yi YU \\ Nanjing University of Finance and Economics, Nanjing City, P.R.China, 210023 \\ guanyamei@sina.com
}

\begin{abstract}
The integration of environmental audit and economic responsibility audit is an environmental responsibility audit. Although there is a demand for environmental responsibility audit inside and outside the enterprise, the importance of environmental auditing is becoming increasingly prominent. However, due to the lack of a systematic and effective environmental responsibility auditing model, Chinese environmental responsibility auditing practice is backward and slow to develop. Therefore, according to the specific characteristics of Chinese enterprises fulfilling the entrusted environmental responsibility and drawing on the ideas of other disciplines, it is necessary to explore a reasonable auditing model suitable for Chinese enterprises' environmental responsibility audit, which is necessary to promote the development of Chinese environmental responsibility audit theory and practice.
\end{abstract}

Keywords-Environmental audit; Economic responsibility audit; Environmental responsibility audit

\section{INTRODUCTION}

Environmental audit and economic responsibility audit have the same functional roles and both have the functions of supervision, verification and evaluation. With the same audit objectives, they can achieve sustained and healthy economic and environmental development and meet the requirements of sustainable development. The audit methods are partly the same. Both of them use the normal methods of auditing; the audit evidence is partly the same, and there is audit evidence that can be shared between them. Based on this, environmental audits and economic responsibility audits can be effectively integrated.

\section{FEASIBILITY ANALYSIS OF INTEGRATION OF} ENVIRONMENTAL AUDITING AND ECONOMIC RESPONSIBILITY AUDITING

\section{A. The goals of environmental audit and economic responsibility audit are consistent}

The report of the 18th National Congress of the People's Republic of China contains such contents. Taking the development path with Chinese characteristics and features, the overall layout has formed a five-in-one development pattern. On the one hand, it can achieve economical high-speed development, that is, a smooth and quality operation. On the other hand, it can ensure the conservation of resources and the protection of the environment. The Five-in-One strategic structure includes five aspects, namely the formation of five in one place in economic construction, political construction, cultural construction, social construction, and ecological civilization construction. In particular, it highlights the conservation of resources and the protection of the environment. The report clearly pointed out the importance of advancing the development strategy of the Five-in-One and also made important arrangements for how to advance the development strategy of the Five-in-One. When implementing the connotation of the report of the 18th National Congress of the Communist Party of China, we must firmly seize the big goal of the Five-in-One, implement the related policies, and specify the direction for the development of socialism with Chinese characteristics. Both the environmental audit and the economic responsibility audit are oriented towards the realization of these five aspects. Therefore, the goal of both of them is to realize the development strategy of the Five-in-One.

\section{B. Consistency of Internal Audit of Environmental Audit and Economic Responsibility Auditing}

Whether the functions, purpose, essential characteristics, connotations of the two or the important influence or the significance of their integration, the two can avoid duplicate evidence after integration, and accordingly can reduce the amount of manpower invested in the audit process, physical and financial resources can thus reduce audit costs and further improve the quality of audit. Therefore, they are organically connected and promote each other, and the effect of binomial integration is far greater than their independence.

\section{THE ESSENTIAL CHARACTERISTICS OF GOVERNMENT ENVIRONMENTAL RESPONSIBILITY AUDIT}

\section{A. Government Environmental Responsibility Auditing Has a High Authority}

The audit of government environmental responsibility is a highly authoritative tool for environmental management because of its high level of hierarchy and independence. This supervision of inspections is stipulated by law and is at the highest stage of monitor and supervision. It is a relatively highlevel resource protection management supervision and has a high level of prestige [1]. The government audit is the supervision of the power of leading cadres from the outside and has strong independence. Differing from the narrow sense of environmental management, it is an external control of the 
implementation of the environmental actions of leading cadres and is independent. The audit supervision inspector is external to the resource protection administrative system, which includes the characteristics of externalities, highlights issues more comprehensively, and results are more fair. It is highly probable that the audited units and the audited leading cadres will be recognized. Therefore, the prestige of environmental responsibility audit will be more recognized.

\section{B. Government Environmental Responsibility Audit Indirectly Realizes Environmental Management Objectives}

The audit of government environmental responsibility is independent because it is outside the environmental management public rights operating system. It should be emphasized that as a result of its indirect environmental management work, the auditing agencies use identities outside the system and supervise the cadres of the authorities to make decisions on the protection of resources and the responsibility of the chief responsible person of the resource management department for the use of state assets and resource management Environmental practices conform to established standards and create new paths for the protection and management of government resources, ultimately achieving the goal of protecting national resources and environmental security.

\section{The Implementation Subjects of Government \\ Environmental Responsibility Auditing are All-sided and Unified}

The diversification of the implementing entity makes it different from the general resource protection management and is a prominent feature of the government's environmental responsibility audit [2]. We must look at the attributes of diversification dialectically. On the one hand, it strengthens the government's environmental responsibility auditing. On the other hand, it can lead to inefficiencies and reciprocity. In order to solve this problem, through expert in-depth research and related to China's specific conditions and related characteristics, we must set up a joint meeting of environmental responsibility audit or professional committee of environmental responsibility audit, to integrate the multi-sector audit implementation main body, to coordinate the parties to make it more diverse and with the properties of integration.

\section{Government Environmental Responsibility Audit Reflects Personalized Management Mode}

The protection of government resource management made by leading cadres is a key target of government environmental responsibility audit. In addition, the government's environmental responsibility audit has focused on the personal responsibility of the government officials and has personalized the government's environmental behavior. In other words, the focus of the government's environmental responsibility audit lies in the inspection of people and the inspection of responsibilities. It is an individual audit of the government officials and reflects the personalized management model.

\section{CONTENTS OF GOVERNMENT ENVIRONMENTAL RESPONSIBILITY AUDIT}

\section{A. Environmental Policy Responsibility}

As a typical public goods, environmental resources have obvious non-excludability and externalities. The market failure resulting from this makes it difficult to guarantee public environmental benefits. Therefore, the government must adopt some regulatory measures to properly intervene to restrict, regulate and guide the behavior of enterprises. The government will make environmental decisions in a fair and reasonable manner in accordance with relevant laws and regulations in order to achieve the goals of sustainable development and safeguard the interests of the public environment. In this process, as the main body of environmental decision-making responsibilities, government departments must assume corresponding responsibility for decision-making. Responsibility of environmental decision-making requires the government to formulate environmental policies, social development and environmental protection plans, and clearly define property rights in order to solve the external problems of environmental resources. For example, through the formulation of an ecological compensation system, an environmental impact assessment system, and an emissions trading system, the market mechanism will be introduced into environmental governance to promote the formation and development of the environmental protection industry, accelerate the transformation of government functions, and make up for market failures.

\section{B. Environmental Executive Responsibility}

The implementation of environmental policies cannot be separated from financial guarantees. Environmental funds are the basic resources for the implementation of environmental policies. The management and use of environmental funds is an important part of environmental policy implementation. In the process of implementing environmental policies and achieving environmental policy objectives, government departments are responsible for environmental funds and environmental projects, including not only the responsibility for the collection, distribution, management, and use of environmental protection funds, but also the responsibility of construction, operation, maintenance, and management of environmental projects. Responsibility of the implementation of environmental responsibility should be in strict accordance with the requirements of relevant laws, regulations, policies and regulations, to ensure timely funding of environmental protection in place, reasonable distribution, use of science, management practices, eliminate private misappropriation, embezzlement, waste and other phenomena; to ensure environmental projects The planning is scientific and reasonable, the operation effect reaches the expected goal, and the maintenance management works effectively, which is in line with the overall requirements of ecological civilization construction. 


\section{Environmental supervision responsibility}

Environmental supervision is part of government functions and can be divided into environmental monitoring, environmental supervision and environmental management. As the main body of environmental supervision, the government uses physical, chemical, biological, remote sensing, and computer technologies to monitor and manage the environment It discovers or predicts environmental problems in a timely manner, and then adopts regulatory measures to restrict and guide corporate behaviors to ease conflict between economic development and the environment protections. Responsibility of environmental supervision requires party committees and governments at all levels, environmental protection agencies, environmental supervision agencies, and agriculture, forestry, and water resources departments, and other responsible entities with environmental supervision and management responsibilities to clarify their own regulatory responsibilities and comprehensively improve environmental monitoring, in accordance with relevant environmental supervision laws and regulatory systems. Supervision, management, strict law enforcement, supervision in place.

\section{IMPLEMENTATION STRATEGY OF GOVERNMENT ENVIRONMENTAL RESPONSIBILITY AUDIT}

\section{A. Establish and improve the overall pattern of government environmental responsibility audit}

Implement cooperative audits and share audit resources. Joint audit, parallel audit, and collaborative audit all form a cooperative audit together. Arrange audit plans rationally and plan the work scientifically. It is necessary to carry out followup audit on environmental governance. By tracking the audit, we can check the performance of the target responsibilities. As for some provinces, we innovatively plan audit programs and scientifically plan audit work to solve problems through practice and research. Widen the verification field and conduct multi-faceted audits. The areas covered by the issue of resource protection are relatively broad. To strengthen the protection and management of resources, it is necessary to broaden the field of auditing, keep up with the rhythm of the times, and conduct diversified audits [3]. Combining environmental responsibility audit with other professional audits, the inclusion of environmental auditing content into other professional audit programs has become a trend. It is believed that it will be the top priority of this verification work in the future.

\section{B. A level and focus of environmental responsibility audit}

The focus is environmental supervision, emphasizing acceptance and inspection, processing and service, and fulfillment of responsibilities. In the audit investigation of the disposal of hazardous wastes that caused environmental pollution in some areas, we found that because the government and relevant responsible departments have no ability to dispose of environmental pollution, there is no clear and effective punishment law for companies that cause environmental pollution. The measures are not enough and supervision fails to make the severity of environmental pollution deepening. It will not only cause environmental problems, but will even cause losses to the entire society, including life and property. This kind of danger is very big and it is something that we do not want to see. Therefore, environmental supervision is an important part of the audit process.

\section{Consolidate and Improve Government Environmental Responsibility Auditing Methods}

Environmental responsibility audits are characterized by strong professionalism, high technical difficulty and many interdisciplinary fields. Under normal circumstances, we will request the support of external experts and assistance in hiring. Integrate professional inspectors and audit analysis at work to arrive at the final audit conclusion. Accelerate the innovation of big data technology and provide software and hardware support for the promotion of big data technology. The functions of data collection, storage, transmission, and analysis of audit institutions are inseparable from good hardware and software environments. The construction of databases is the key link. Audit institutions should establish a database centered on environmental big data and capable of high-speed reading and high-capacity storage. It includes not only the standardized information of the audited unit's basic information, financial and financial information, and environmental monitoring data, but also non-standardized information such as environmental protection standards, environmental governance plans, and related industry internal standards. At the same time, it should speed up the research and development of audit software to develop a fully functional and easy-to-use audit software, so that we can break the barriers between big data technology and auditors.

\section{CONCLUSION}

We must vigorously strengthen the construction of the relevant legal system of environmental responsibility audit, and on this basis, improve the relevant pursuit system. We should vigorously strengthen the training of talents in the direction of environmental responsibility audit and improve the overall quality and professional ability of environmental responsibility auditors. We should promote the development of environmental responsibility auditing in a comprehensive and in-depth way.

\section{ACKNOWLEDGMENT}

This research was financially supported by National Social Science Fund (18AGL007).

This research was financially supported by Jiangsu Province Social Science Fund (18WTA005).

\section{REFERENCES}

[1] Wendy Green, Stuart Taylor. Factors that Influence Perceptions of Greenhouse Gas Assurance Provider Quality [J]. International Journal of Auditing, 2013, 17:288-307.

[2] Huggins, A., Green, W. \& Simnett, R.. The competitive market for assurance engagements on greenhouse gas information: is there a role from the accounting profession? [J]. Current Issues in Auditing, 2011, 5, (2):A1-A12.

[3] Roger simnett, Michael Nugent, Anna Huggins. Developing an International Assurance Standard on Carbon Emissions Disclosures [J]. Accounting Horizons, 2009, 23(4):23-34. 